\title{
Gender and Absolute 'l' of a Person: Scope of Contraposition and New Contexts of Identity
}

\author{
D. Zharkimbayeva \\ Shahkarim State University, \\ Semey, Kazakhstan \\ R. Imanzhussip \\ L.N.Gumilyov Eurasian National University, \\ Astana, Kazakhstan \\ A. Mukatayeva \\ Shahkarim State University, \\ Semey, Kazakhstan

\section{Zhumaxanova} \\ L.N.Gumilyov Eurasian National University, \\ Astana, Kazakhstan

\section{K. Bolyssova}

Shahkarim State University, Semey, Kazakhstan

Doi: 10.2478/jesr-2019-0025

\section{Abstract}

The aim of the study is to investigate gender and absolute 'l' of a person as scope of contraposition and new contexts of identity. The methodological basis of the study of the philosophy of gender is the idea of the Absolute 'l' of a person, scope of contraposition of gender and sex, new contexts of gender identification. Person is inseparable from his essence, which determines his gender. As a result, identity is an open system, therefore the process of changing the identity of both men and women is an interdependent change of mindsets complementing and enriching each other and the world around. In conclusion, the male, which is obviously not changeable enough, can be ultimately completed to the female principle. People are attracted to men who prone to dialogue and mercy. But the feminine principle, which constitutes all the beauty in a person, is instant, and cannot have rigidity, totalitarian firm determination, in a word, those qualities that should have a long-term perspective.

Keywords: Modern, Epoch, Transcendental, Subject, Gender

\section{Introduction}

Consideration of the being of sex in the aspect of the substantive and socio-cultural areas allows to reveal the realization of human's natural and social roles. Whilst the essence of a person is 
associated with learning about infinity and limits, which is related to the transcendental ontology of knowledge. Gender always questions the realism or idealism of human existence. Gender is linked to the notion of the fundamental purpose of philosophy. Although sex is a kind of a starting position (with it a person is actually born), sex is determined not only by biological factors, genetic differences, the 'gender' itself is a multipolar structure. It is a question of a certain socialization of a person in society, as a result of which the male and the female are not only the spiritual products of their societies, but the decisive here is proven to be a person's 'ego' ('I'), which establishes and forms the values for body differences. Gender is not merely the inner sex, but the spiritual, Absolute 'l' of a person, which, nevertheless, depends on cultures and social space-time. The historical and philosophical differentiation between the concepts of 'sex' and 'gender' formed the basis of the theory of gender as a cultural metaphor, which forms gender stereotypes in the public consciousness. Thus 'the male' is identified with power, energy, rationality, culture, and 'the female' - with weakness, passivity, emotionality, nature.

Gender theory claims that social differences between men and women are not determined by their anatomical sex, but are socially constructed. The term gender refers to the set of cultural and social norms that society creates for men and women. Moreover, the idea of normative masculinity and normative femininity are formed on the principle of binary opposition and subordination. Thus, gender is one of the mechanisms of social stratification of society, which in combination with such socio-demographic factors as race, nationality, class, age, forms a complex system of social hierarchy. The analysis of the process of constructing a gender system is interesting not only from the point of view of its social consequences. It appears that a significant role in the formation of gender differences was played by various intellectual theories, including philosophical ones. The sexual difference cannot be addressed in isolation from the functioning of our knowledge of the body and bodily being. Knowledge cannot be Absolute and 'pure', it cannot be isolated from its practical application in a wide chain of discursive contexts (Bahremand, 2015; Razavi et al, 2015; Adedeji, 2018).

In this respect, gender is associated with the concept of the super-semantic paradigm of knowledge. Gender in a certain manner is the truth as the being of the unity of knowledge. This is evidenced by the urge of the theory of concept Absolute truth in Fichte's phenomenology from 1804-1811 (Barth, 2007). Fichte designated science teaching, i.e. the teaching about science, which radically transforms its understanding, as a central part of his philosophy. The usual idea of science is that it is a set of 'scientific' disciplines, each of which has its own special subject and its own 'scientific' methods. And in this case, no questions are raised about how it is possible to learn the subjects of sciences, which seem different from the subjective thinking that cognizes them, how and on what basis ideas about these subjects are formed, what is the 'scientific character' of scientific methods. Consequently, science remains largely unconscious and, strictly speaking, unscientific. The mentioned transformation of Fichte's understanding of science was precisely that he has attempted to answer these questions in a satisfactory manner.

According to Guilherme (2010), when Fichte attempts to answer the question 'How is knowledge possible at all?', Fichte aims at providing the foundation of all experience, a first principle which grounds all experience, and this first principle is the Absolute ' $I$ '. Fichte was a foundationalist (just as all his predecessors and contemporaries) and as such he understood that the sceptic threat could only be overcome by a sound foundation to all knowledge. But the concept of the Absolute ' $\mathrm{l}$ ' is more than a mere epistemological foundation; it is rather the cornerstone, it is the first principle of his whole Wissenschaftslehre project. That is, Fichte (and his contemporaries) understood that philosophy ought to be systematic, and as such he attempted to derive his system from this first principle. This means that Philosophy for Fichte was a science just as Physics and Biology are, and as such, it required a first principle which could serve as the foundation of all philosophical enquiry.

As McNeill (1966) suggests, in order to understand what Fichte meant by the ego, we must keep in mind the distinction he made between the spontaneous activity of the pure ego and the philosopher's consciousness of that activity. The ego as a spontaneous activity is the ground of consciousness which is not itself conscious. Thus this ego is said to exist in itself (in sich) but not for itself (fur sich). Fichte distinguishes here between the initial state of pure being (sein) of the ego 
and its state of conscious being (dasein). By means of the abstractive reflection of the philosopher, the pure ego as conscious being comes to be originally (urspriingiich) for itself. In this intellectual intuition, the pure ego is said to posit itself (sich setzen). Through denying the individuality in the Absolute 'l', Fichte alters the spirituality into something impersonal that can no longer be characterized as I, much less as absolute 'l'. Fichte continues to clarify and change some of the provisions of 'Wissenschaftslehre', so he gradually applies the concept 'Spirituality', which is more general, instead of the absolute 'l'. As early as 1797 in the 'Second introduction to the Wissenschaftslehre' Fichte virtually replaced the absolute ' $l$ ' by the concept of impersonal superhuman mind.

As Lomonosov (2009) noted, Fichte's 'l' is Absolute indeed, both in form and content, although solely in one respect: in terms of experience and rational thinking. Later Hegel would write more fundamentally and in detail about true thinking as a concrete process of cognition in itself, but before approaching it, one must learn the position of transcendental idealism and through it approach the understanding of the eternal idea of Christianity. Contrary to the positivist-scientific or traditional-metaphysical way of knowledge, which dogmatically proceeds from the outerly given grounds, the transcendent one, first developed by Fichte, comes only from the own, the absolute grounds, or Absolute 'l'. Therefore, all the diversity of phenomena and entities he reduces to a universal method of activities and learning, which gradually realizes (manifests) itself in world history.

\section{Materials and Methods}

The methodological basis of the study of the philosophy of gender is the idea of the Absolute 'l' of a person, the scope of contraposition of gender and sex, new contexts of gender identification. A person is inseparable from his essence, which determines his gender. Human substantiality, his gender component defines his emotional world. A person, in this respect, depends on education, beliefs, religion, value orientations, lifestyle, mentality, and worldview. The learning of gender, however, is based on interpersonality and feeling, a sense of freedom as a substantive characteristic and a guarantee of reality itself (Buchheim, 1997). Therefore, there is a distinction between sex and gender. Gender is rather the inner sex of a person, the social and spiritual sex associated with the 'self', the Absolute ' $\mathrm{l}$ ' of a person. We deviate from understanding gender as something purely male or female in ways of thinking. Gender means common humanity in culture and the study of gender is especially attractive in the manner it is.

\section{Results and Discussion}

A person moves from sex to gender in the course of its evolution. Through games and clothes, a child from an early age begins to identify itself as either male or female. Though all children like someone (adults or other children) to play with them. The game not only represents a breakthrough into the realm of freedom but also reduces all things and events to their ultimate semantic expression. It is not merely about a significant role cultural environment itself plays in the early stages of socialization, not only about a game-defining the scope of 'appropriate', which differs from culture to culture but also about the very 'inability to do anything other than play' characteristic of adults. This means, 'that their goal is not to play, but to forget something else while playing' (Fichte, 1993). If a serious thought occurs to a person, a thought he or she cannot cope with, then, of course, it can be put aside. However, a person stands up to the disturbing thought and uses all the power to present it in a rather funny way. A person does not tolerate his gender in its original serious form. After all, a person resorts to knowledge, which establishes values for physical and spiritual differences. These values, taken in their gender, cultural incarnation, vary according to cultures, social groups and time.

Gender is one of the most important and fundamental social categories. Gender perceptions largely determine the structure of societies, and at the same time, they do not exist outside of society. This is one of the social universals. Gender perceptions have a number of reasons for different properties. First of all, in any society, there is a biological division of people into male and 
female. It inevitably affects human life at its earliest stages. Each newborn is referred by doctors and parents to one or the other group on a simple basis: by its anatomical features. The very first gender perceptions associated with a person's sex suggest the further range of social views, attitudes, stereotypes and models within which the person will be considered. The nature of gender as a social category is dynamic. At the earliest stages of life, children learn gender characteristics in the process of socialization, that is, in the process of acquiring knowledge about society and learning the rules and roles that help them become a part of society. It is important to emphasize that a people's gender perceptions (of themselves and others) are constantly evolving and transforming throughout all their life, just as the process of socialization itself lasts throughout life.

Gender behavior, as well as linguistic behavior, is an acquired behavior that a person learns in the process of interaction with other people. Consequently, the acquisition of gender and language behavioral stereotypes has a mutual effect: the manifestation of gender is reflected in language elements, and language activities are gender-specific. Therefore, the study of language can tell a lot about the nature, structure, formation and constant reproduction of gender relations in society. According to Azarova (2001), a person's personality is formed in the process of everyday communication with others. The culture of a certain society is accepted by a person not as something external, imposed from the outside, but as consisting of models of appropriate behavior that arise in communication and are constantly strengthened insofar as people interact together with the living conditions. Important factors influencing the formation of moral gender stereotypes are also verbal communication with other people, direct experience with the object of a certain gender, 'nonverbal communication', etc. In childhood, the image is of particular importance, because for a child the key element is an image of the surrounding objects and people, copying which he/she assimilates a certain set of social attitudes in an undivided form.

At the social level, the formation of moral gender stereotypes is primarily determined by the notions of masculinity/femininity, which are characteristic of this culture and largely determine it. Moral gender stereotypes, while functioning within a particular culture, tend to change if there are a number of changes in the culture itself. It is possible to trace the change of some moral gender stereotypes by others throughout the history of mankind. Moral gender stereotypes are a stable set of representations, peculiar for a particular society within a certain culture, formed on the basis of ideas about masculinitylfemininity, enshrined in a variety of symbols, accumulating the experience of many generations about the proper and improper behavior of men and women, about the features of their moral appearance, and, as part of culture, transmitted from generation to generation in the process of socialization. Therefore, it is a culture that has a decisive influence on the formation and change of moral gender stereotypes. To make a more accurate definition of gender, understanding of its dynamic nature, it is important to trace the specifics of its interpretation not only within the framework of different sciences but also within different eras in the process of modernization. Classical, modernist and postmodern approaches demonstrate a significant transformation in the interpretation of the concepts of sex and gender, indicate their time and temporal nature:

- The classical model of knowledge interprets 'gender' as a single socio-biological characteristic by which people define each other as 'men' or 'women'. Gender is reduced here to a set of behavioral patterns expected from the representatives of a particular sex in a particular culture, which fixes the asymmetry of socially-determined forms of behavior and self-consciousness of men and women;

- Modern science considers gender as a structure of personal qualities and ways of social interaction fixed in culture, with which each individual of certain sex identifies himself/herself;

- An intermediate position between the modernist and post-modernist direction is the concept of gender as a system of interpersonal interaction, through which the concept of the male and the female as the basic categories of social order is created, approved and reproduced;

- Postmodernists overcome the dual approach to the interpretation of human sex and offer to consider it apart from any connection with biological categories. It is not about the priority of social construct (gender) over biological reality (sex), as it can be noted in the 
modernist approach. The biological determinism of classical thinking, according to which gender is a socio-cultural reflection of sexual dimorphism existing in nature, is also overcome here. In postmodern studies, the biological reality is considered as the effect of special social perception of the bodily component of gender.

It is natural to highlight such an important feature of gender as its dynamic nature. The justification of gender as a dynamic category is closely connected with the transformation processes of post-industrial society. The essential sides of gender are not biological predetermination and constancy, but variability and dynamism. The mechanism that causes gender dynamics involves two levels: on the one hand, the level of structures and institutions, and on the other, the level of the individual and his/her practices. The change in the relationship between these two levels - structural and individual - determines the vector of gender dynamics. In the context of the theory of the gender social constructing, this category is understood as an organized model of social relations between men and women that determines their social relations in key institutions of society (as well as is defined or constructed by them). This approach is based on two assumptions. First, it is believed that gender is constructed through socialization, division of labor, the system of gender roles, etc. Second, it is constructed by the people themselves at the level of their consciousness (i.e. gender identification), and by the adoption of the established norms and roles and the corresponding 'adjustment' to these norms and roles. Gender is a powerful tool that produces, reproduces and legitimizes the choices and boundaries prescribed by a person's gender.

As Shmeleva and Khaisarova (2013) suggest, the theory of social constructing of gender is based on the analytical distinction between biological sex and the social process of sex attribution (sex categorization). Gender is seen as the work of the society in sex attribution. Therefore, gender can be defined as the relationship of interaction in which the male and the female are manifested, perceived as natural entities. The gender relation is constructed as the relation of social inequality. In terms of the theoretical assumption of the construction of gender, it becomes possible to put forward a provision on its reconstruction and change. The relationship between the male and the female may change. The gender display can be a means of both confirming and destroying the established gender order. In order to ensure the possibility of social change, it is necessary to contextualize the relationship of inequality between the existing concepts of the male and the female. The notion of gender as a social construct implies that sex, gender and sexuality are derived from the social context. The social reality of gender relations is structured by other social relations that are important for the reproduction of the existing social order.

According to Svechkareva (2011), the idea of unity and equivalence of both sexes as two necessary principles of the Universum, inherent in some philosophical systems, coexists with the nurtured paternal tradition of the principle of male superiority and female existential lack of selfsufficiency. In the context of the entrenchment in the philosophical thought of traditional views on man and woman, their role in the family and society, the very question of the origins of gender asymmetry could not occur, because it would question what was considered as undisputable a priori. One of the manifestations of real humanism will be the interaction, based on the principle of complementarity, which allows for the grouping of different entities under one nature and assumes that these entities mutually enrich each other: Complementarity does not imply the transformation of interacting parties (complementing the components) into the struggling opposites. This means that none of them seeks to take a dominant position and act as a system of organizing principle. This "Removes the alienation caused by the fact that external, incomprehensible principles of rational behavior are imposed on a person. Svechkareva (2011) considers it appropriate to expand the field of ethical complementarity, including the principle of complementarity of male and female principles in morality. The female dimension included in morality as a factor of its humanization can indirectly stimulate the way out of the global crisis of the world and man, the crisis caused by technological civilization and masculine culture.

Individualization and pluralization of social existence entail the inevitability of recognition not only of different types of masculinity/femininity but also of such individual lifestyles that do not fit into this dichotomy. Identity is an open system, therefore the process of changing the identity of both men and women is an interdependent change of mindsets complementing and enriching each other and the world around. A fundamental openness to the world implies that people facing the 
world are self-identified, influenced by the world, and change themselves, but in this change, the world is affected as well. According to Trubina (2005), self-identification of an individual is his/her establishment of the identity with himself/herself through the active change of external influence. In this regard, the main structural components of self-identification are the following:

1. Identity 'l' (consciousness, mind).

2. Identification of permanent or continuing unity of activity (personality, individuality, character) through the change of activity or behavior. Among other things, this implies: a) the existence of memory; b) the ability to identify itself; $C$ ) the ability to never lose knowledge of something that happened or happens to you ('Ego', 'l').

\subsection{The idea of 'complementarity' and the Absolute 'l' of a person}

We believe that the semantic measurement of gender is determined primarily by the philosophical definition of this concept, the problem of its 'fitting' into a single overall world picture. We are particularly interested in the application of an additional way of thinking to the gender aspects of the theory of knowledge, to the aspect of the absolute measurement of the person's ' $\mathrm{l}$ '. It should be mentioned that the epistemological and ontological consequences of the idea of 'complementarity' can be outlined in the interpretation of Niels Bohr's statement denying that Heisenberg's principle of 'uncertainty' is the principle of 'limited measurability' (Grünbaum, 1957). Otherwise, some generalizations of 'complementarity' face the ill fate. Basing on this, Grünbaum criticizes specific ways of applying 'complementarity' in biology and in the doctrine of the soul. Grünbaum disagrees with Niels Boron in the study validity of the concept of life as 'elementary'.

The discussion that unfolded in the late 50 s of XX century between Alexander (1956), is of great interest. Alexander (1956) criticized McKay's statement, which qualified scientific and religious consideration of reality as complementary. This discussion can be applied to the description of sex and gender dichotomy. When describing gender and sex, differentiating between the concepts of 'gender' and 'sex', we are, in fact, deeply concerned about the suggestion to treat two descriptions of the same situation as equally necessary. Either term 'sex' has unnecessary meaning, or 'gender', or they are certain alternatives. Alexander (1956) suggest the latter to be descriptions that although differ, but at the same time allow a mutual transfer, without excluding each other (Alexander, 1956). In the meantime, the idea of complementarity is not a universal panacea, it is a relation that needs careful consideration, in terms of the concepts of 'sex' and 'gender' as well. Gender enables to create a geographical map of gender culture, which would reflect the economic, political, religious characteristics of a person and people, historical events reflected in the mosaic of gender consciousness of different parts of the world. Though gender requires careful treatment, including in terms of aspire to spread the idea of complementarity beyond the boundaries of physics.

Gender, as we believe, is still connected with the idea of the validity of complementary thinking. Gender is associated with the inability to exhaust the essence of life phenomena with the help of conceptual systems of physics and biology. One can treat the complementarity of physicochemical and biological approaches to the study of social life as a methodological alternative to the overly direct reductionism. Be that as it may, gender deals with finite rather than infinite objects. Nevertheless, human knowledge has a priori prerequisites, 'which, in turn, are corrected and reinterpreted under the reverse effect of substantive knowledge obtained with their help'. In the framework of this model, complementarity reveals the mutual justification of physics and anthropology, sex and gender. The proposed approach, in any respect, is found upon dialectics. Though dialectics itself may vary. In this study, we grounded on materialistic dialectics as the most complete and free from one-sidedness doctrine of the development of nature, society and thinking.

\subsection{The idea of forming the time of a gender in the mind}

Now the concept of 'gender' in terms of the idea of forming the time in the mind should be discussed. This formation was discussed in the works of (Gaidenko, 1979). In Lauth's works 
temporal being was analyzed in terms of the content of consciousness, then from the standpoint of designing the consciousness in the temporal dimension (Lauth, 1981). In the work of Gaidenko 'Philosophy of Fichte and modernity', the problem of designing, formation of consciousness in time is discussed not only from the standpoint of the gap of individuality and transcendental deduction of the human body, its sex and gender, but also from the perspective of the problems of intersubjectivity in transcendental idealism, from the perspective of the problem of nature and the concept of the Absolute in the late Fichte. The works of Lukjanow (1997) reveal the meaning of the transcendental doctrine of the nature of Fichte, where the transcendental doctrine of nature is considered in its relation to the idea of spirituality. Some authors consider Fichte's transcendental position of 'I' in the light of metaphysics of spirit (Fabbianelli, 2012; Abilgaziyeva et al, 2018).

It should be noted that the existence of numerous other ' $I$ ' in the unity of 'l' - is no more a paradox than the phenomenon of our awareness of sex and gender. A person feels himself/herself to be a male and a female in the temporality of his/her existence. We understand that not only the present and the past being, which once was the present and even the expected, can be present in the consciousness at the same time, but that, through the consciousness of the internal, spiritual time, any object of the external, cultural world can be self-determined. It is possible, in this regard, to recall E. Husserl, who developed the idea of the phenomenology of the 'internal' consciousness of time. Gender as a certain connection with the essential-substantive features of its socio-cultural image, places it into the sphere of hunting for the stability, and philosophy thereby acts as a justification for the Absolute. The philosophy of gender, in effect, develops as a heuristic tool to justify absolute existence. However, the Absolute, absolute 'l' is interpreted by the authors in terms of 'unreflective' ultimate prerequisites of knowledge (Timofeev, 2015; Fichte, 1796).

The 'l' of gender, in its absolute measurement, should not isolate itself from the human (in the sense of 'humanity') society to which a person himself/herself is constantly striving. Gender is, in this respect, a certain ' $I$ ' that still has its 'You' and its 'We', its community of co-existing people in a natural and moral setting. Freedom of ' $\mathrm{l}$ ' as an absolute manifestation of its essential power is impossible without the choice of another 'l'. Another 'l' in order to become a gender, i.e. to realize the inner temporality of the transcendental ' $l$ ' must carefully realize its memory of the past, which does not deactualize the present, but brings to life our true ' $l$ ', aimed at society and overcoming the technocratic spirit, gender allows a person to be independent in the field of socio-cultural relations from the public itself. A person, together with his/her sex and gender, is a self-valuable creature. $\mathrm{His} / \mathrm{her}$ being is a goal itself. The process of consolidation, the formation of Homo sapiens allows understanding the meaning of gender. It should be mentioned that the human history of gender is no longer a history of making sense of meaninglessness. We may be able to manage without a mirror 'copy' of the perfect world, where the gender component becomes substantive or cultural. However, the words of M. Scheler may be recalled here: If God is omnipotent and significant how he could create such a broken person as 'l'. The very purpose to delve into the fate of existence involves the development of a serious version of it, i.e. human self-formation as a harmonic unity of the essential power of Homo sapiens himself.

\section{Conclusion}

Therefore, we have identified the point that consideration of gender without sex is impossible, from an ontological point of view. Gender awareness formed based on the traditions of any nation reflects the substantive characteristics of the representatives of sex, which objectified gender assessment. In any case, however, gender appears not only as of the 'inner' sex but also acquires existence through its representation as a fact of consciousness. Each person is intended to express the human race in his own way by mixing its elements. Gender, as can be seen, contributes to the fact that humanity was discovered, by all means, to show its essence in the fullness of space and time, to realize its diversity. When we correlate gender with the inner sex and, especially, with the absolute 'l' of a person, we reveal not only the scope of the contraposition of sex and gender but also new contexts of gender identification. It is a gender that forms the scope of 'appropriate', which in different cultures has different semantic significance. Thus, if some authors try to contrast the 'position' and 'basis', the biological sex and gender, as a set of social and spiritual roles, refers to 
the very beginning of the Fichte's philosophy, G. Wheeler, for example, opposes 'spirit' ('Geist') to the 'ghost' ('Gespenst') and declares Fichte's nominalism in 'Wissenschaftslehre' to be a new method.

This method implies that sex and gender should henceforth be analyzed as facts of consciousness, but at the same time, they should have the ability to critical evaluation with the achievement of recognition by other ' $l$ '. From these positions not only gentleness and mercy, tolerance and altruism, dialogue and aspiration to search for consent have been prescribed to the female line of behavior, but these qualities, probably, constitute the essence of male's as well. The male and the female should not deny each other at the same time and in the same respect. Thus, the male, which is obviously not changeable enough, can be ultimately completed to the female principle. People are attracted to men who prone to dialogue and mercy. But the feminine principle, which constitutes all the beauty in a person, is instant, and cannot have rigidity, totalitarian firm determination, in a word, those qualities that should have a long-term perspective. And yet, the male and the female are complementary to each other. We think that the nature of the discussions about sex and gender suggests that gender is associated with the absolute 'l' of a person. During the formation of the world of absolute values, sexual attractivity of a person is crystallized.

The authors exploring the essence of sex often believe that this essence appears as a dialectical unity of physical, mental and spiritual 'l' (Baranova, 2012). Indeed, human sex is formed in the process of distancing the spiritual and physical principles. Sex, however, unlike gender, is connected with the idea of harmony of these principles, especially since gender, obviously, is associated with the justification of the idea that the human body is not just a creation of nature, but a 'tool of free will', which realizes itself in the complex modern world. Therefore, according to Gaidenko's (1979) reconstruction of Fichte's theory of physicality, human, in contrast to the animal, comes into this world purely helpless and incomplete. The human body, its sex, and gender must be fully formed by the 'spirit', i.e. free moral will.

\section{References}

Abilgaziyeva, Z. K., Janzakova, S. I., \& Nurgaliyeva, S. A. (2018). Speech activity among the junior students in teaching foreign languages. Opción, 34(85-2), 627-652.

Adedeji, T. (2018). Revitalizing Mathematics Education Preparation in Nigeria for National Development: An Innovative View. International Electronic Journal of Mathematics Education, 13(3), 315-320. https://doi.org/10.12973/iejme/3923

Alexander, P. (1956). Complementary description. Mind. 65, 258, 145-165.

Azarova, E. A. (2001). Proceedings from V conference, devoted to the theory and history of women's movement: The influence of culture of the formation and measurement of gender moral stereotypes. S. Petersburg: Sankt-Peterburgskoe filosofskoe obshchestvo, 213-219.

Bahremand, A. (2015). The concept of translation in different teaching approaches and methods. UCT Journal of Social Sciences and Humanities Research, 3(1), 5-9.

Baranova, O. M. (2012). Phenomena of love and sex in socio-philosophical dimension. Orenburg: OOO IPK 'Universitet', 176.

Barth, R. (2007). Wahrheit als Sein von Einheit. Die gewißheitstheoretische Reformulierung des absoluten Wahrheitsbegriffs in Fichtes Phänomenologie von 1804-1. Fichte- Studien, Bd.31, Amsterdam - New York, 4, 103-117.

Buchheim, T. (1997). Das ,Gefühy der Freiheit' als ein widersprüchliches Pfand ihrer Realität. Fichte - Studien, Bd. 11. Amsterdam -Atlanta, QA, 396.

Fabbianelli, F. (2012). Fichtes transzendentaler Ansatz in der Metaphysik des Geistes von Bertrando Spaventa. Fichte - Studien. Bd. 38, 307.

Fichte, J. G. (1993). Main features of modern era. V. Volzhskiy (Ed.). S. Petersburg: Mifril, 2, 798.

Fichte, J.G. (1796). Werke. Auswahl in sechs Bänden. F. Medicus (Ed.). Hamburg: Meiner, 2, 64-65.

Gaidenko, P. P. (1979). Fichte's philosophy and modernity. Moscow: Mysl, 288.

Guilherme, A. (2010). Fichte: Kantian or Spinozian? Three Interpretations of the Absolute I. South African Journal of Philosophy, 29(1), 1-16.

Lauth, R. (1981). Die Konstitution der zeit im Bewußtsein. Hamburg: Meiner, 129.

Lomonosov, A. G. (2009). Transcendental philosophy and Christian religion. Vestnik LGU im. A. S. Pushkin, 2(3), 88-96. 
Lukjanow, A. V. (1997). Der Sinn der transzendentalen Naturlehre Fichtes. Fichte- Studien, Bd. 11, Amsterdam -Atlanta, QA, 396.

McNeill, J. J. (1966). The Blondelian synthesis: a study of the influence of German philosophical sources on the formation of Blondel's method and thought. Leiden: Brill.

Razavi, S. M., Nasirian, M., \& Afkhami, I. (2015). The effectiveness sleep hygiene training on the job performance of employees Shift or rotating shifts parvadeh tabas coal companies in. UCT Journal of Management and Accounting Studies, 3(1), 5-7.

Shmeleva, N. B., \& Khaisarova, G. M. (2013). Gnoseological grounds for emergence and development of the theory of gender social constructing. Vestnik Kazanskogo tekhnologicheskogo universiteta, 16(18), 346351.

Svechkareva, V. R. (2011). Problem of gender within the context of complementary ethics. Vestnik AGTU, 1, 70-72.

Timofeev, A. V. (2015). The hunt for sustainability: Philosophy as a justification of the Absolutes. In Philosophy, Science, Culture (collection of scientific articles dedicated to the $60^{\text {th }}$ anniversary of Professor A. A. Shestakov. Samara: 000 Ofort, Samara State architecture and Construction University, 320.

Trubina, E. G. (2005). The told I: problem of personal identity in modern philosophy. Ekaterinburg: UrO RAN. 